\title{
RESEARCHPAPER
}

\section{Survey and collection of some uncommon macrofungi of Gorakhpur district (U.P.)}

\author{
RAVINDER PAL SINGH, PRATIMA VISHWAKARMA, POOJA SINGH AND N. N. TRIPATHI \\ Department of Botany, Deen Dayal Upadhyay Gorakhpur University, GORAKHPUR (U.P.) INDIA \\ Email : ravinder.20033@gmail.com
}

Article Info : Received : 04.04.2017; Revised : 11.08.2017; Accepted : 08.09.2017

Mushrooms are important component of human diet throughout the world due to their specific taste, nutritional value and medicinal importance. In present study the survey of different forests of Gorakhpur district between the years $2014-2016$ were done to collect the macrofungi. The collected macrofungi were identified on the basis of morphological and microscopic characters. In all 20 macrofungi were collected and identified. Out of 20 macrofungi studied Abortiporus biennis, Amanita virosa, Bovista plumbea, Ganoderma lucidum, Lepista inversa and Trametes versicolor were abundant and grow gregariously during rainy season. These macrofungi were well photographed and preserved in dry as well as in wet condition for the further study. This study indicates a great variation in climatic condition of Gorakhpur which made it possible for the abundance and variability of macrofungi in this area.

Key words : Diversity, Mushroom, Nutritional, Medicinal, Macrofungi

How to cite this paper : Singh, Ravinder Pal, Vishwakarma, Pratima, Singh, Pooja and Tripathi, N.N. (2017). Survey and collection of some uncommon macrofungi of Gorakhpur district (U.P.). Asian J. Bio. Sci., 12 (2) : 126-133.DOI : 10.15740/HAS/AJBS/12.2/126-133. 